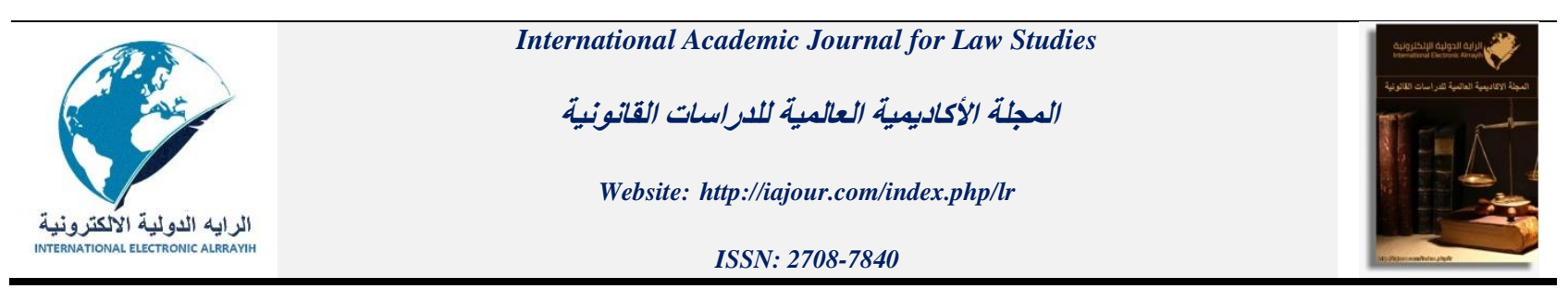

\title{
مسؤولية الطبيب عن تفاقم الحالة الصحية للمريض
}

\author{
د. زينة حسين علوان \\ كلبة الحقوق /جامعة النهربين
}

zena.h@nahrainuniv.edu.iq

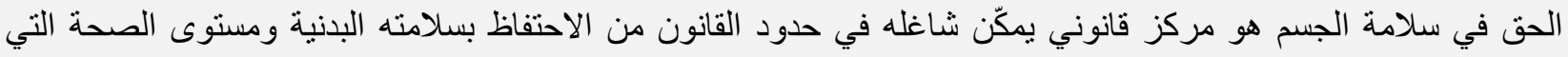

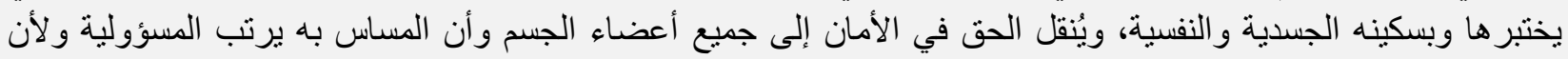

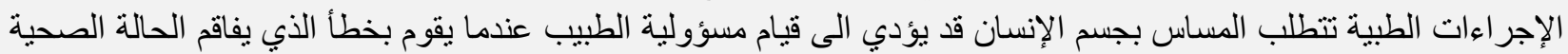
للمريض وتكييف هذه المسؤولية باعتبار ها مسؤولية مهنية.

الكلمات المفتاحية: تفاقم الحالة الصحية، مسؤولية، الطبيب، الخطأ المهني.

\section{المقدمة}

تعد المسؤولية الطبية من مو اضيع الساعة نظر اللاخطاء الطبية الكثيرة وما يثور حول طبيعة هذه الاخطاء ومدى الزام ام او عدم الطاء

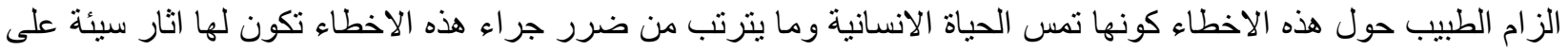
المريض وان مفهوم الخطأ الطبي هو مفهوم واسع يشمل كل عمل خاطئ يصدر عن الطن الطبيب اثناء ممارسته لعمله وفي بحثنا



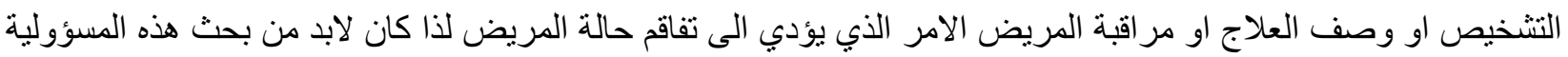

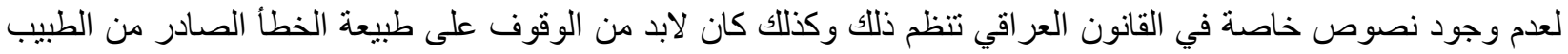

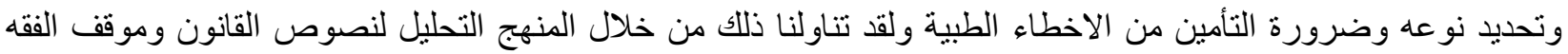

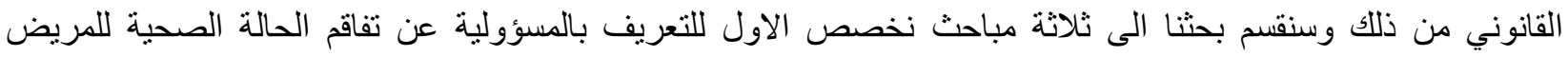

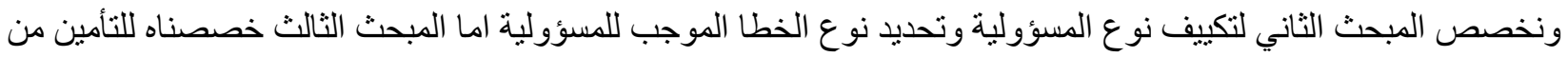


المبحث الاول : مفهوم مسؤولية الطبيب عن تفاقم الحالة الصحية للمريض

المطلب الأول : الحق في الحفاظ على المستوى الصولة الصحي للجسم

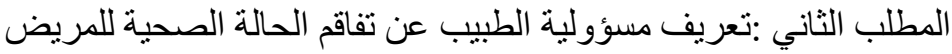

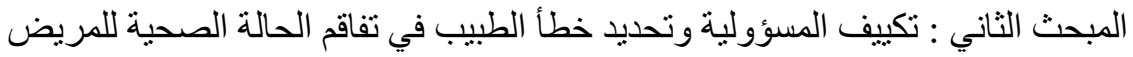

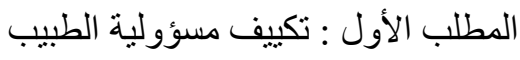

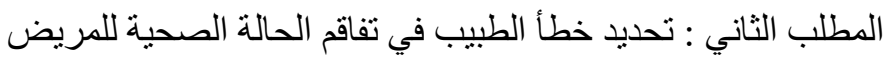
المبحث الثالث : التأمين من المسؤولية

خاتمة

\section{المبحث الأول}

\section{مفهوم مسؤولية الطبيب عن تفاقم الحالة الصحية للمريض}

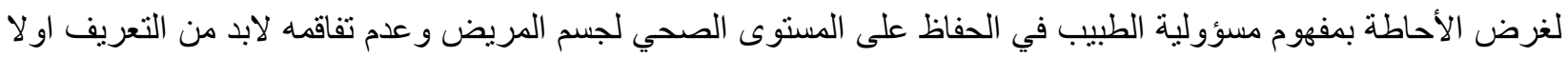
بالحق بالحفاظ على المستوى الصحي للجسم في المطلب الاول ونتناول في المطلب الثاني تعريف مسؤولية الطبيب في حال تفاقم الحالة الصحية للمريض. بالف المبن.

\section{المطلب الأول}

\section{الحق في الحفاظ على المستوى الصحي للجسم}

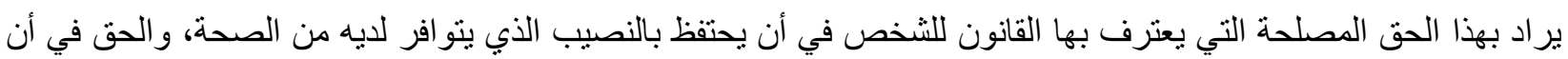

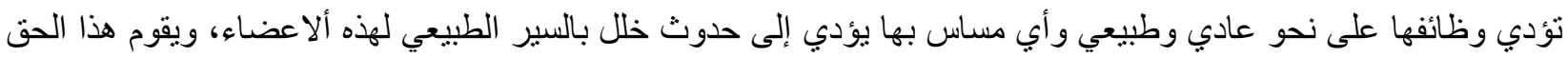

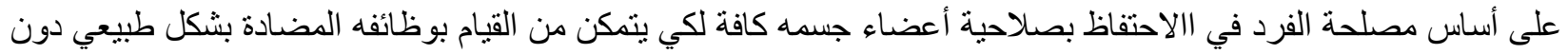



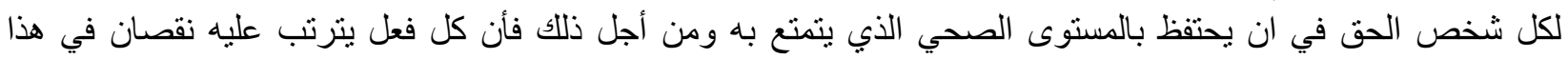

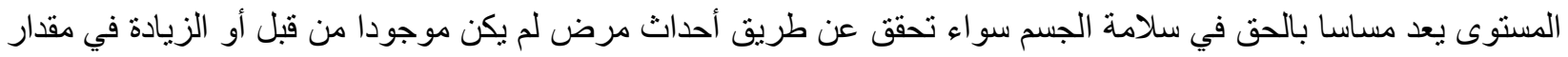
مرض كان المريض يعانيه من قبل ،فكل فعل يؤدي الى تعطيل بعض الجسم او اجهزته الداخلية عن اداء وظيفتها الطبيعية

تعطلا

تاما او مؤقتا يتوفر به المساس بسلامة الجسم 2 ـوقد اكد فقهاء القانون ان مصلحة الفرد في عدم انخفاض مستو اه الصحي الصدي

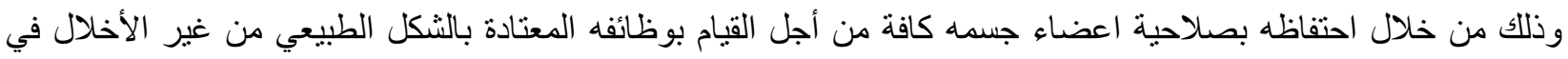

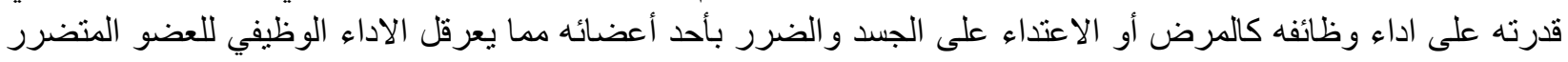

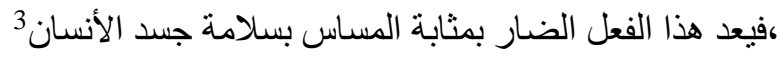

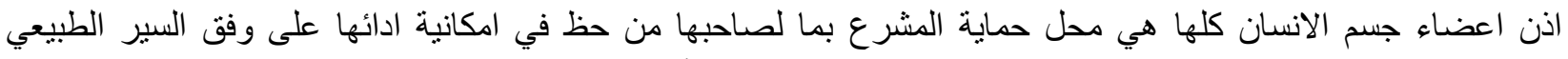

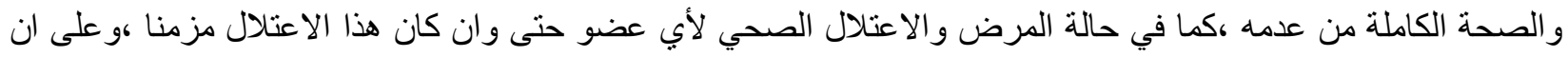

1. احمد شوقي عمر ابو خطوة القانون الجنائي والطب الحديث المطبعة العربية الحديثة القاهرة 1986ص21،بيرك فارس حسين حقوق الثخصية



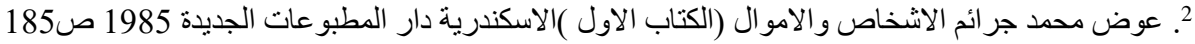

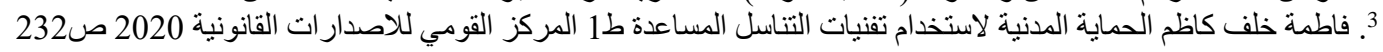


تسير وظائف الاعضاء جميعا كما هو مقدر لها مع احتفاظ صاحبها دون مساس بها ومتحررا من الالام البدنية جميعها ،فأن

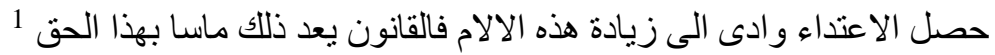

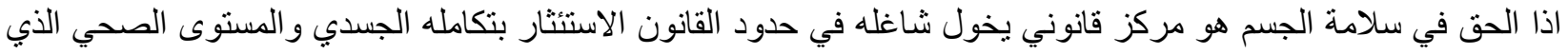


واعضاء الجسم . وان الحق في حرمة الجسم يعتبر من اهم عناصر الحق في الحياة الخاصة لأنه لايمكن للشخص ان يتمتع بحياته الا اذا كان في

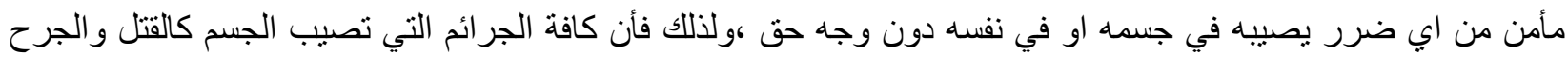

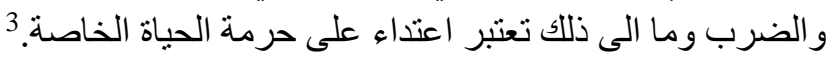

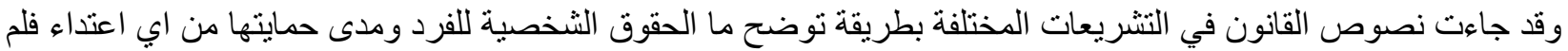

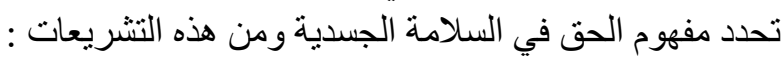
1.في التشريع العر اقي نص القانون المدني العر اقي رقم 40 لسنة 1951 على حماية الحق في سلامة الجسم وذللك في المادة

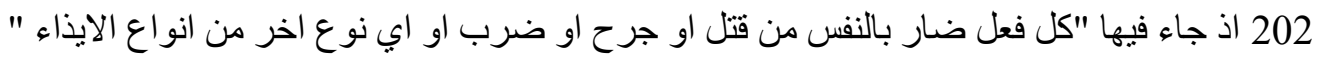

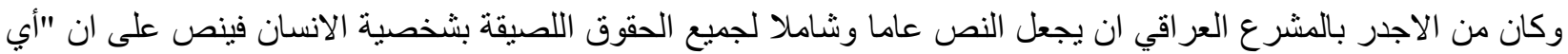

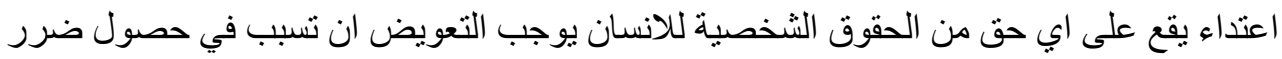

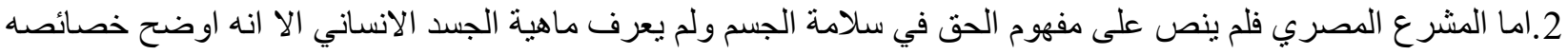

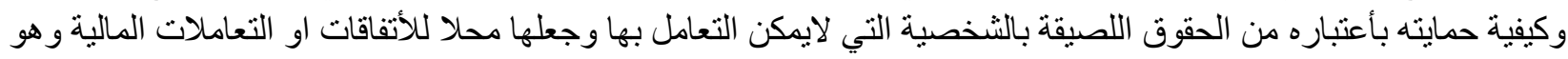

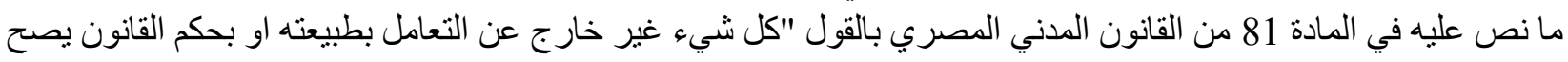

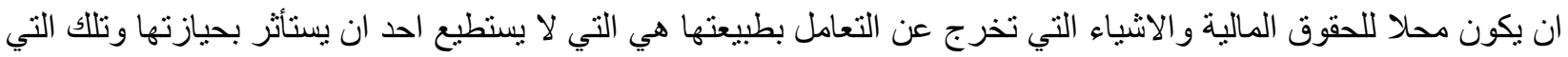

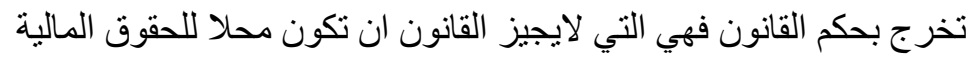

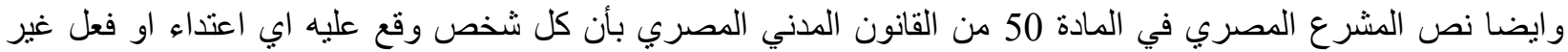

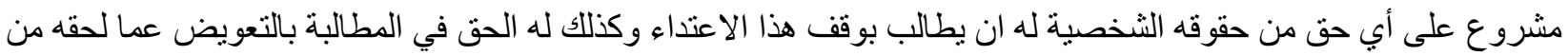

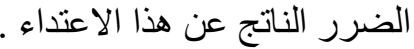

3.اما القانون المدني الفرنسي لسنة النهاء 1804 المعدل فقد نص على حرمة جسم الانسان وذللك بحمايته من الاعتداء الذي يقع عليه

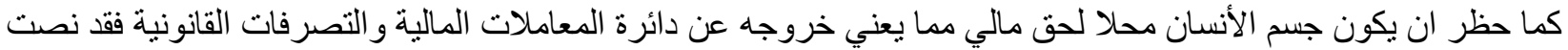

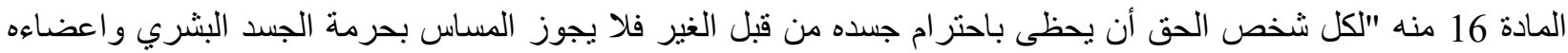

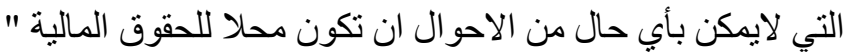

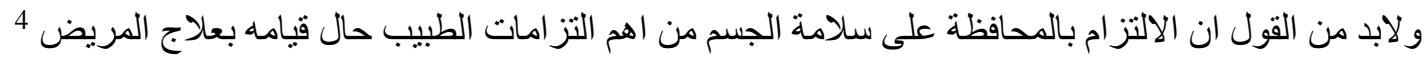



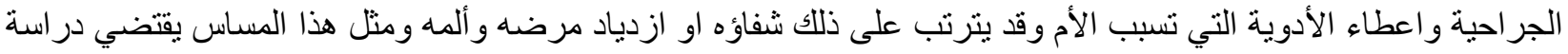
هذه المسؤولية عمن يباثرون هذه الاعمال وفي المبحث الثاني سنبحث في مسؤولية الطبيب في حال تفاقم الحالة الصحية

ل لمريض

المطلب الثاني

\section{تعريف مسؤولية الطبيب عن تفاقم الحالة الصحية للمريض}

تفاقم من الناحية اللغوية: تفاقم (فعل) تفاقم المرض :تز ايد شدة ، تضخم ،تفاقم الامر استفحل شره تفاقم (أسم) مصدر تفاقم حاول

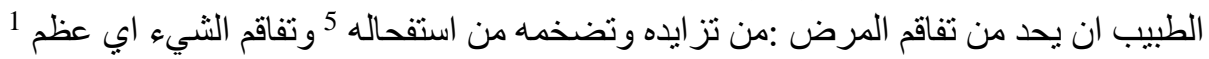

1.". حسين عبد الصاحب جر ائم الاعتداء على حق الانسان في التكامل الجسدي اطروحة دكتور راه جامعة بغداد 2005ص280 -60

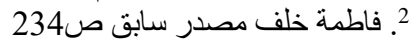

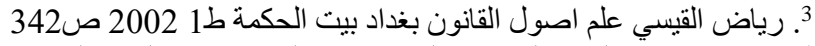

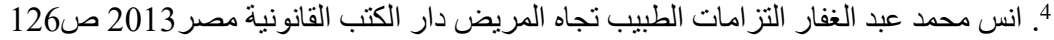

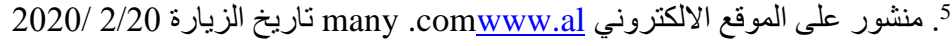


اما تعريف التفاقم اصطلاحا :فهو التغير الذي يطر أ على ذات الضرر بزيادة العناصر المكونة له عما كانت في السابق 2 و عرف التفاقم ايضا بالنسبة للأصابة الجسدية بأنه التغير الذاتي للاصابة الجسدية بزيادة حجم الضرر او زيادة العناصر المكونة

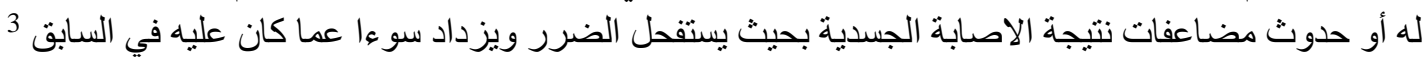



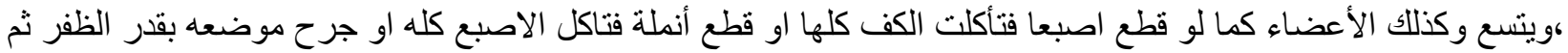

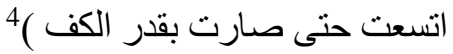

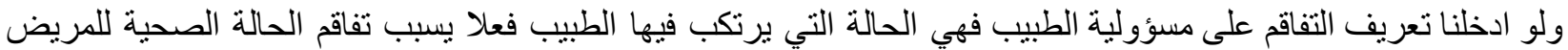



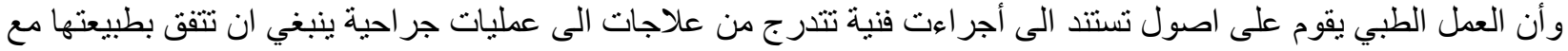

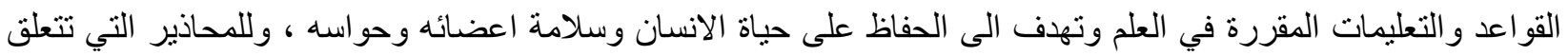

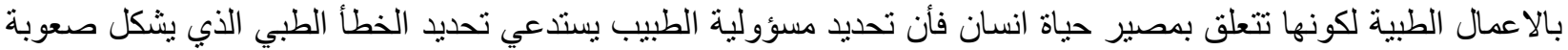

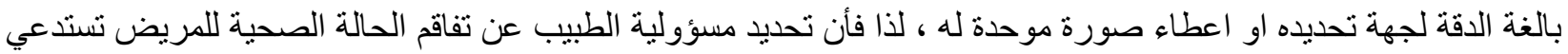
منا در اسة طبيعة هذه المسؤولية وتحديد الخطأ.

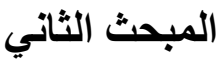

\section{تكييف المسؤولية وتحديا نوع الخطأ}

نتناول في هذا المبحث تكييف مسؤولية الطبيب في حال تفاقم الحالة الصحية للمريض في المطلب الاول ونبحث في خطا الطبيب في المطلب الثاني

\section{المطلب الأول}

\section{تكييف مسؤولية الطبيب}

لم ينظم المشرع في العراق و لافي الدول العربية مسؤولية الطبيب بنصوص خاصة لذا ينبغي الرجوع الى القواعد العامة في المسؤولية وقد أجمع الفقهاء في فرنسا ومصر 6 على أن أصل التزام الطبيب في مو اجهة المريض ألتز اما عاما بالحرص و العناية وأن يلتزم بشفاء المريض انما يبذل عنايته وحرصه لأن نتيجة شفاء المريض أمر أحتمالي غير مؤكد سواء بذلك وجد الفئ الألتزام



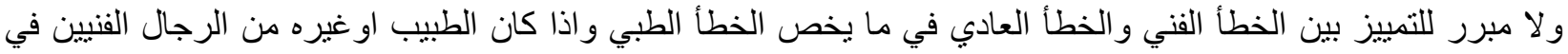

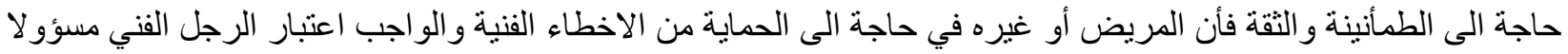

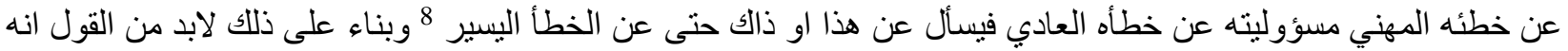

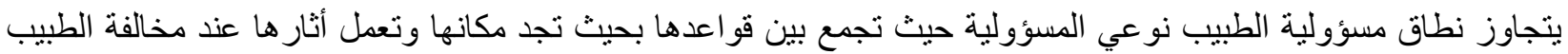
لقواعد و اداب مهنية وتجد مصدر ها فيه أكثر من وجوده في العقد ،و هذا الطابع المهني الناتج عن مخالفة الواجب المهن المهني هو

1. ابن منظور لسان العرب ج7 ،دار الحديث ،القاهرة ، 144 ،

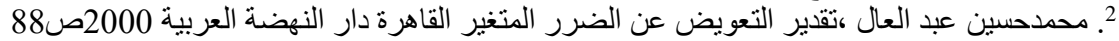

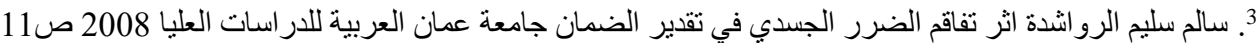

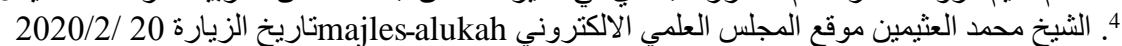

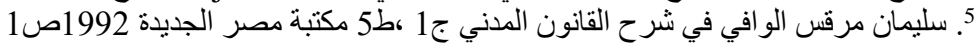

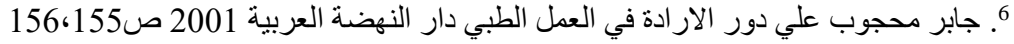

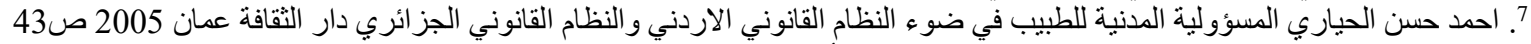

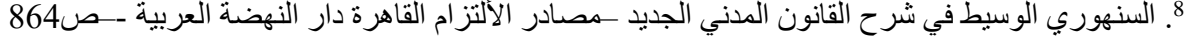




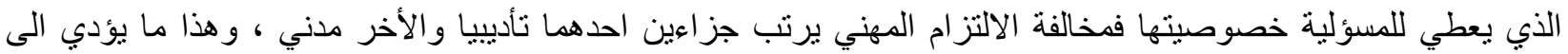
صعوبة الفصل بين احكام النوعين من المسؤولية ،كما يتعذر في نفس الوقت القول بأنطباق أحداهما على المهني.

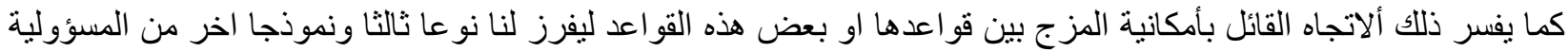

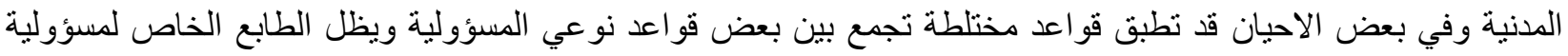

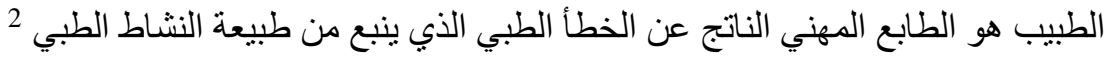

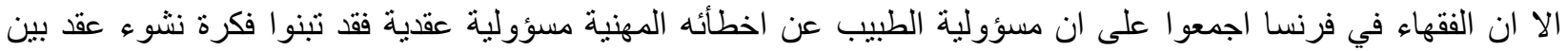

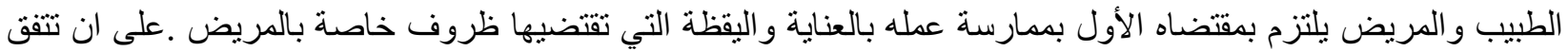

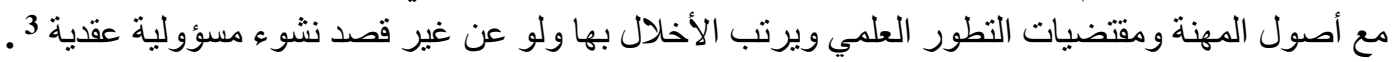

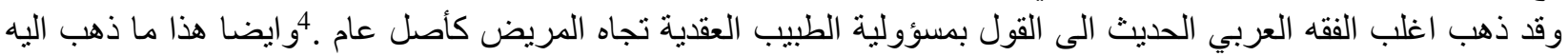
القانون المدني العر اقي في حال وجود اتفاق بين الطبيب و المريض تكون الفئ المسؤولية عقدية ويلتزم الطبيب ببذل العنائ العناية وفي حال

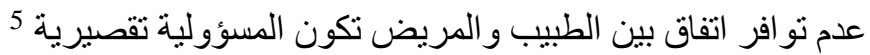

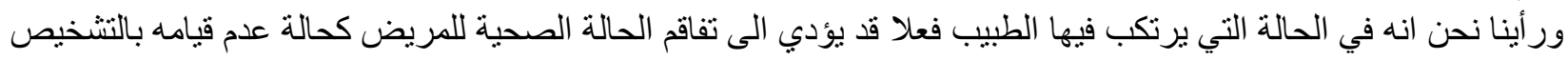

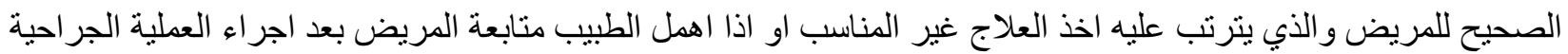

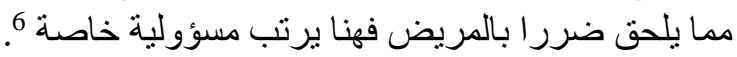

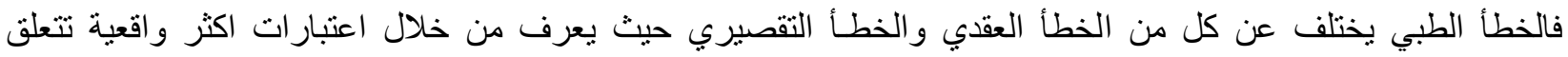

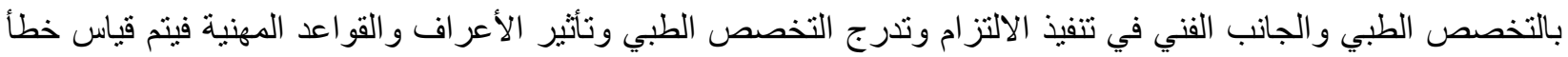

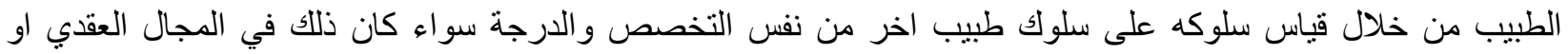

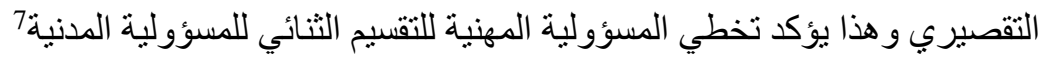



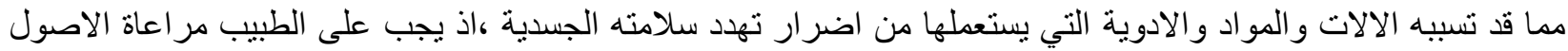

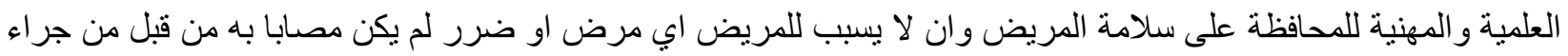

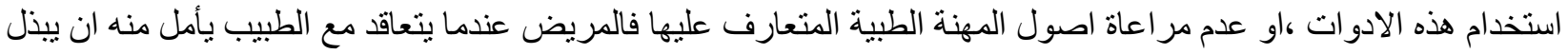

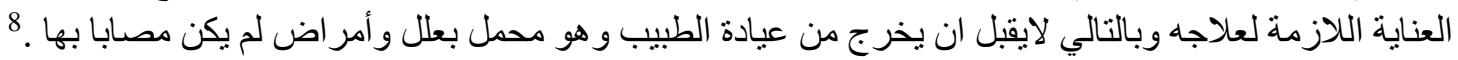

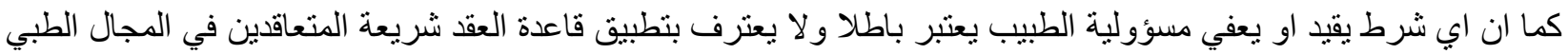

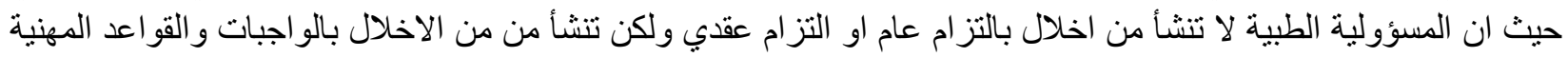

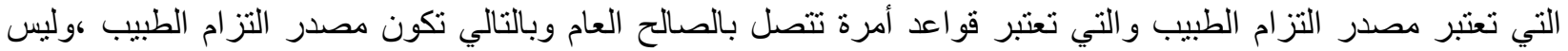

9 مصدر التزامه العقد لذا ان أطر اف العقد الطبي ليس بأستطاعتهم التعديل في الالتزامات المهنية التي تفرضها قواعد اخلاقيات المهنة واعرافها

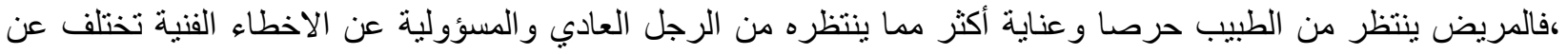

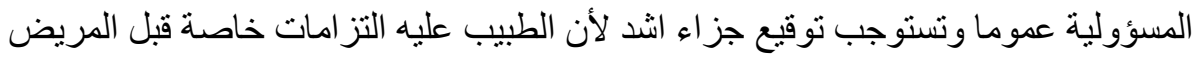

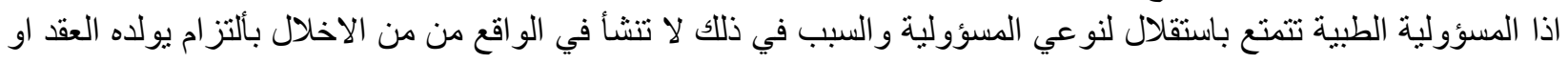

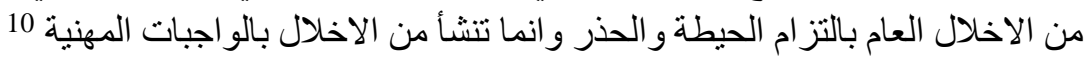

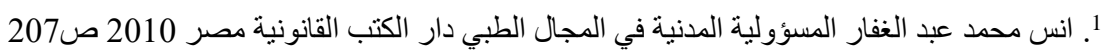

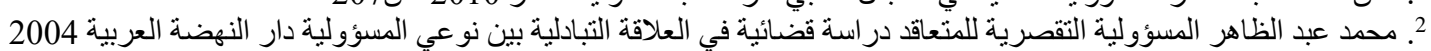
3.

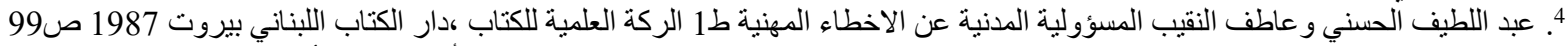

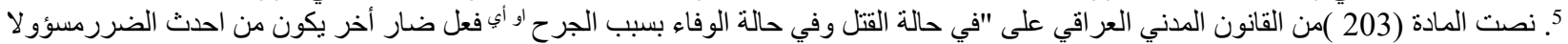

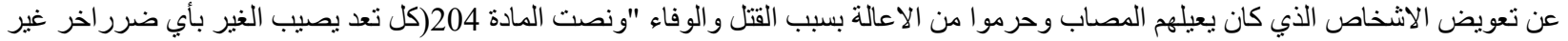

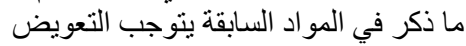

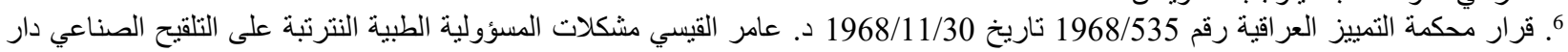

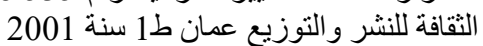
7. انس عبد الغفار المسؤولية المدنية في المجال الطبية الطبي مصدر سابق 200

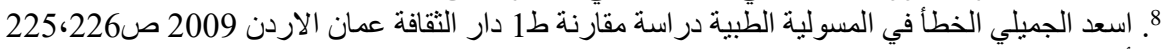

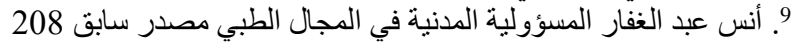

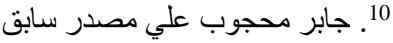


وتقام مسؤولية الطبيب المهنية بأعتبار ان المشرع حين تطلبه لثهادة الطب1 ،ار اد من ذلك تنظيم المهنة وعدم ترك وحماية

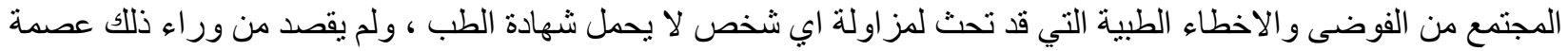

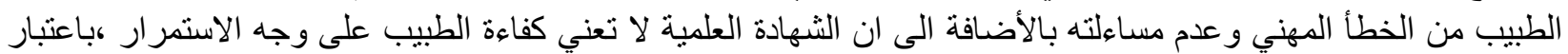

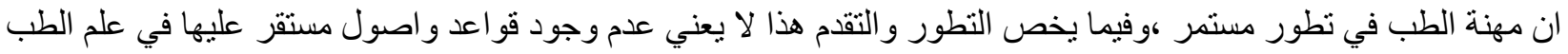
على مدى السنو ات ،و على الطبيب ان يلتزم ويتقيد بها وقت تنفيذ عمله ،وان تجاوزه لها بحجة التقدم و التطور لا ينفي عنه الخطأ المهني

وقد اخذ القضاء العر اقي بهذا الاتجاه الفقهي في مساءلة الطبيب عن كل خطأ يرتكبه وبغض النظر عن نوعه او جسامته ولكن



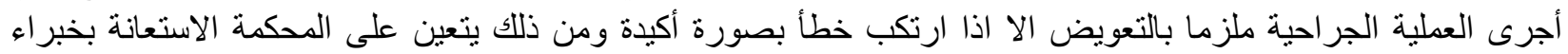

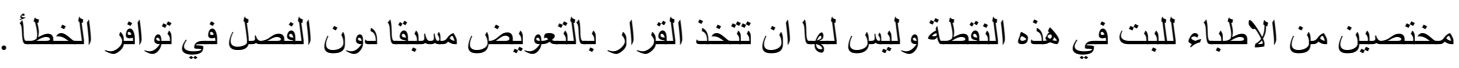

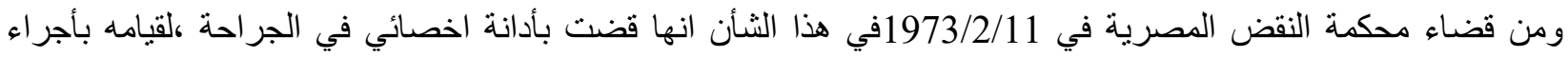



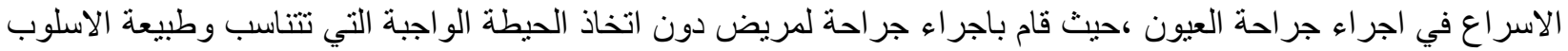
الذيى اختاره ،فعرض المريض بذاء فراء فلك لحدوث المضاعفات السيئة في العينين معا في وقت واحد الامر الذي انتهى الى فقد

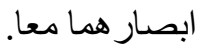

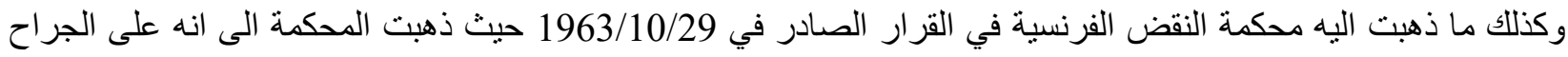

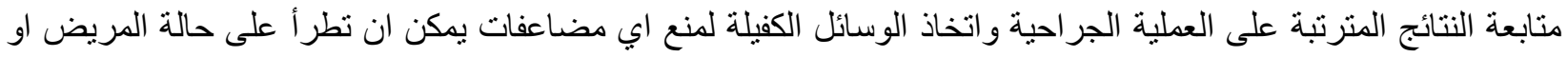



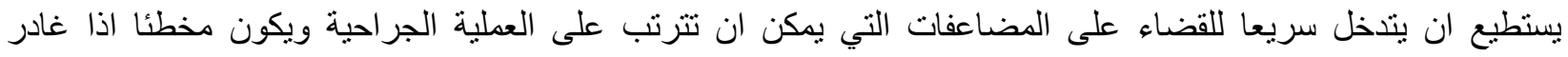

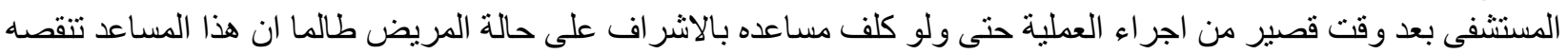

الخبرة و التخصص بعد

المطلب الثاني

\section{تحديد خطأ الطبيب في تفاقم الحالة الصحية للمريض}

الخطا الطبي فعل يصدر ممن يمارس العمل الطبي ويكون غير متفق مع الاصول والمعطيات الطبية المستقرة او المعاصرة او

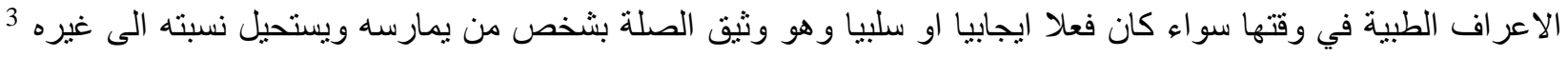

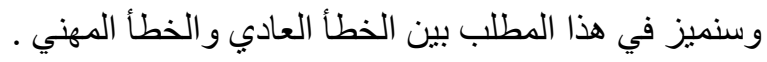

الخطا العادي

الخطأ العادي بالنسبة للطبيب هو الخطأ الخارج عن المهنة فالخطا العادي اذا هو الذي يصدر من اي شخص ولأ الخا علاقة لها

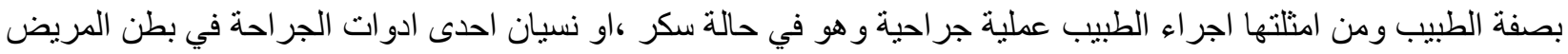

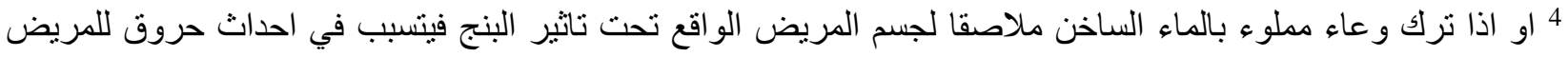

1. أحنصت المادة 3 من قانون نقابة الاطباء على "لا يجوز للطبيب ممارسة المهنة في العراق الا بعد انتمائه الى النقابة وحصوله على شهادة التسجيل 2. همام محمد يعقوب نظرة عن حالات قيام وانتفاء مسؤولية الطبيب في القانون المدني العر اقي بحث مقام الى مجلة كلية القانون والعلوم السياسية العدد5

262 ص 2020

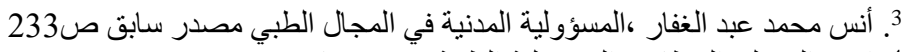

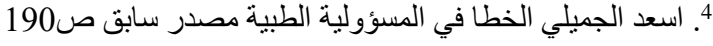


وينتج عن هذه الاعمال المادية خطا يسمى بالخطأ العادي ،يسأل عنه الطبيب كما يسأل عنه اب شخص اذا انحرف عن سلوك

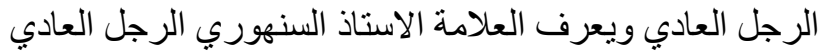
او المعتاد بانه ( الثخص العندي العادي الذي يمثل جمهور الناس فلا هو خارق الذكاء شديد اليقظة فيرتفع الى الذروة ولا هو محدود



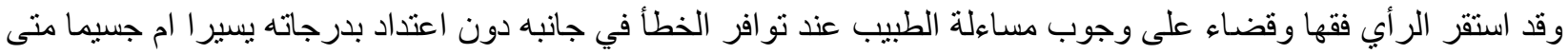



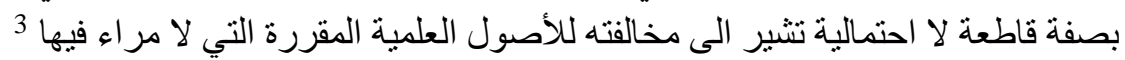

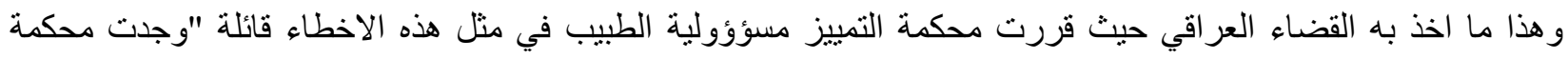

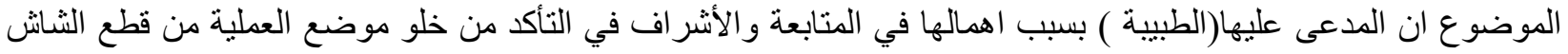

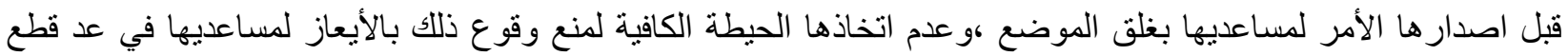

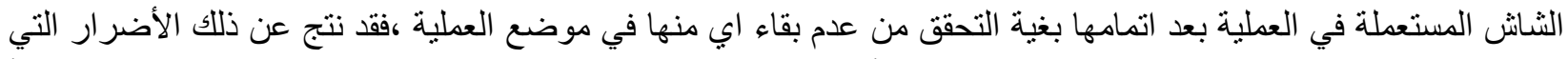

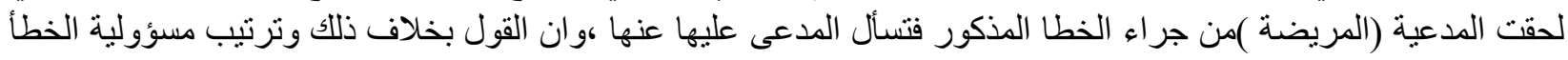

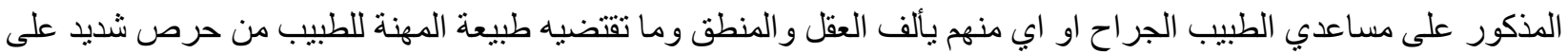

حياة المريض الذي أودع ثقينه العالية فيه"

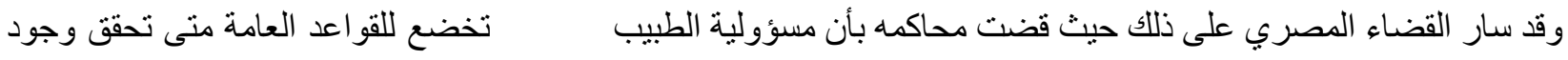

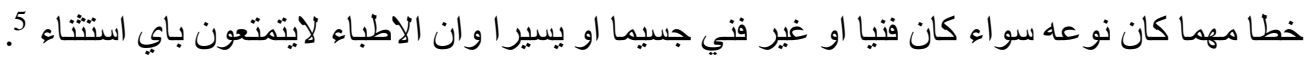

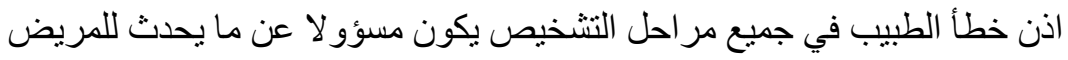

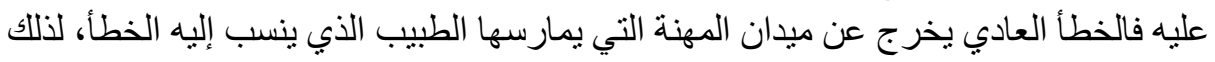

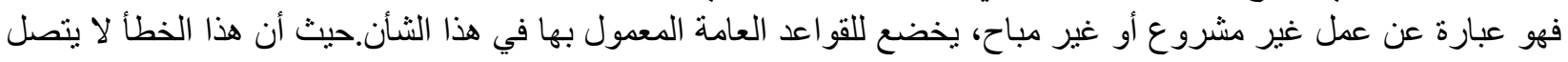

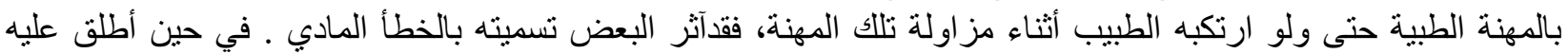
البعض الآخر اسم الخطأ الواضح.

الفرع الثاني

الخطأ المهني

هو الخطا الداخل في نطاق المهنة التي يزاولها الشخص صاحب تلاك المهنة فهو اخلال رجل الطب بالقو اعد العلمية والفنية التي



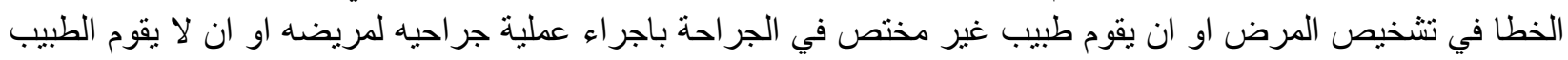

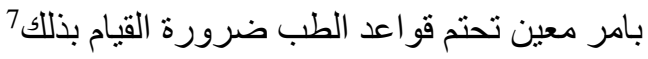

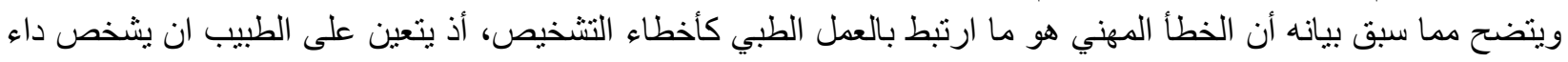

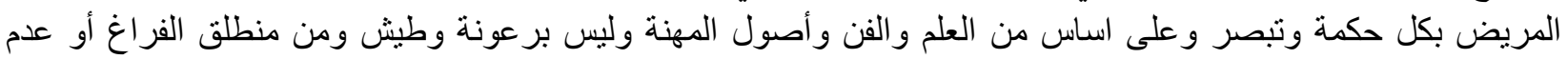

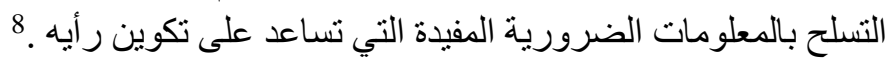

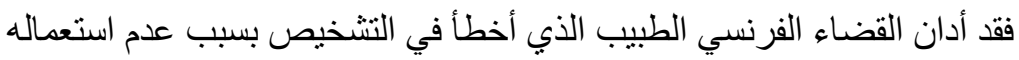
الأشعة و الفحص الكهربائي، إذ جرى العمل على استخدام مثل هذه الوسائل في هذه الحالة المعروضة.

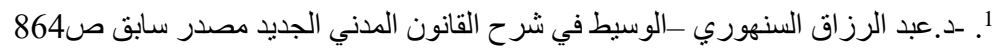

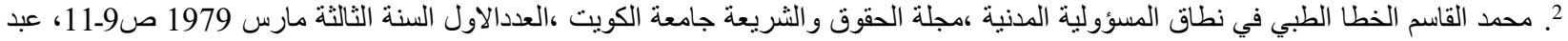

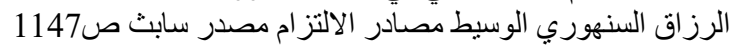

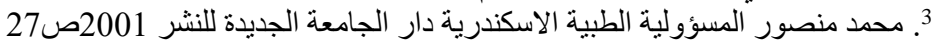

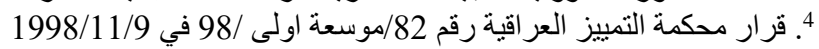

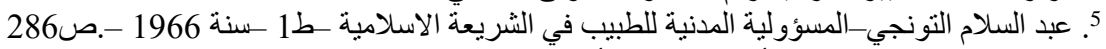

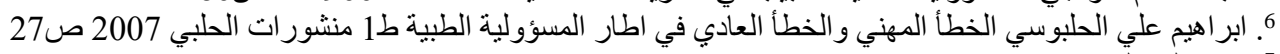


8. ابر اهيم الحلبوسي مصدر سابق ص22 
عليه. ومن أمتلة الأخطاء الفنية (المهنية) في العلاج ما قضت به محكمة النقض الفرنسية من تقرير لمسؤولية الطبيب نتيجة

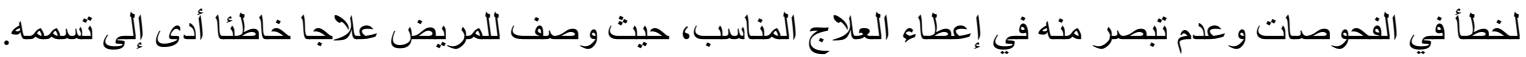

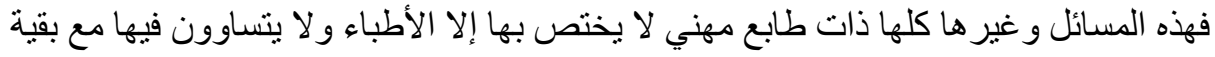

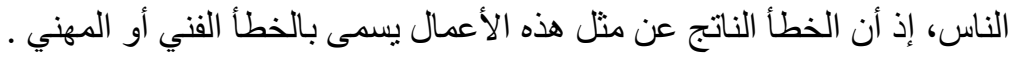

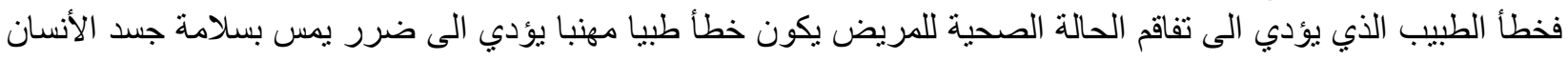

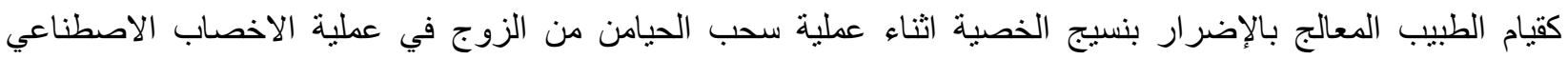
الخارجي مما يؤدي الى حصول خلل في عمل هذه الغذة التناسلية ومن ثم تعطيل هذا العضو من القيام بوظائفه بالثكل الطبيعي التئي

و الأمثلة على ذلك كثيرة، إذ أن مخالفة المبادئ الأساسية في علم الطب، و الحقائق الثابتة

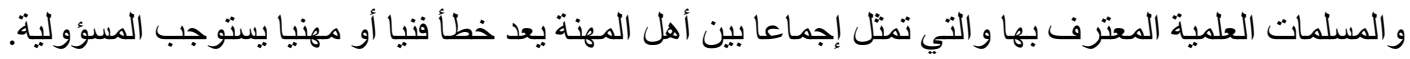

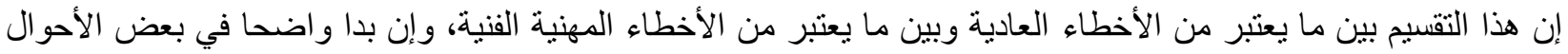

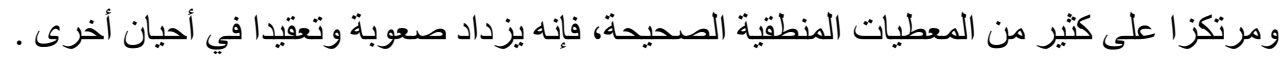
ذللك أن الطبيب الذي يشخص اعلي حالة المريض و هو في حالة سكر يرتكب خطأ ماديا يسأل عنه.

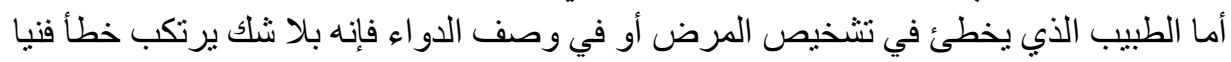

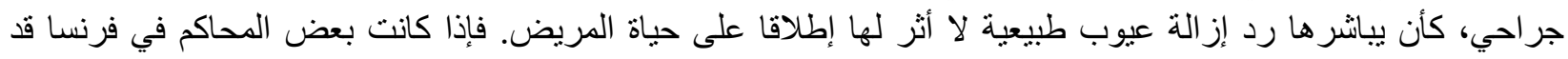

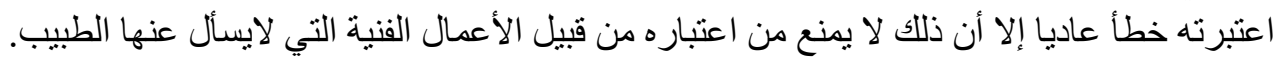

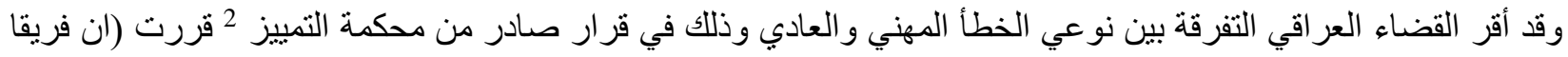

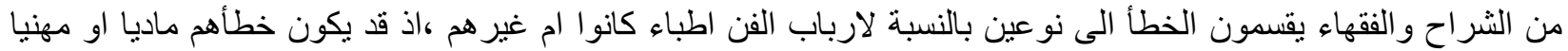



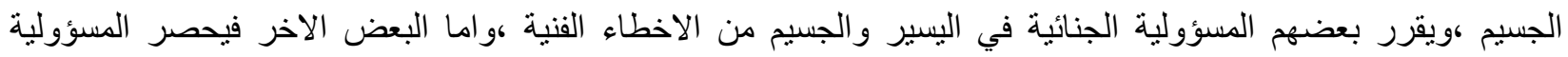
الجنائية في الخطأ الجسيم فقط لأن الطب علم سريع التطور يتصارع فيه قديمه وحديثه صر اعا مستمرا ...) وهذا هو التجاه

القضاء في مصر وفرنسا 3

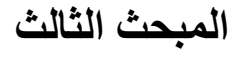

\section{التأمين من المسؤولية}

تتمثل فكرة التأمين من المسؤولية بوجود شخص ما يخثى أن يكون مسؤو لا عما يصيب الغير من ضرر فيقوم بأبرام عقد تأمين

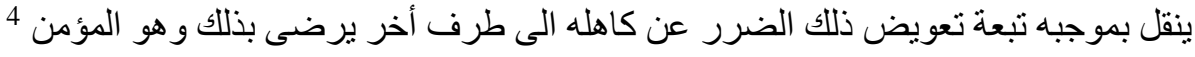

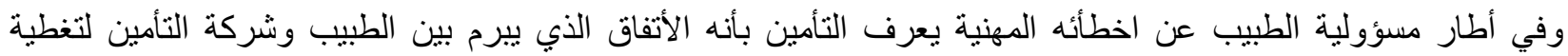

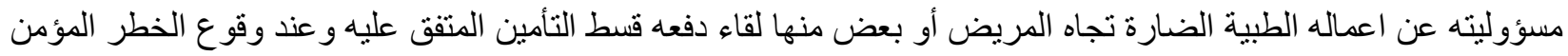

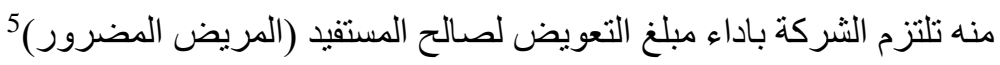

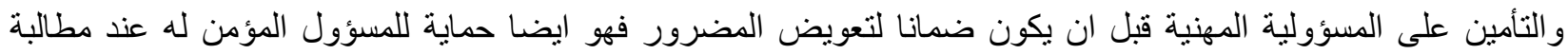

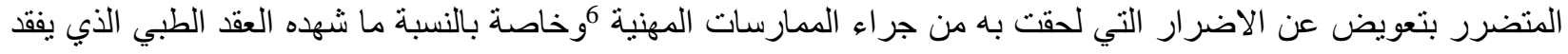
الى خاصية التوقع للمسؤولية التي قد تترنب على الطبيب .لهدف تفادي تحمل عبء التعويض منفردين عن الأضرار التي قد الطي

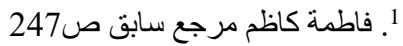

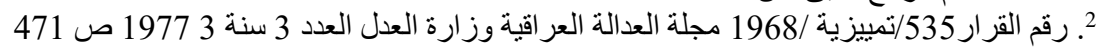

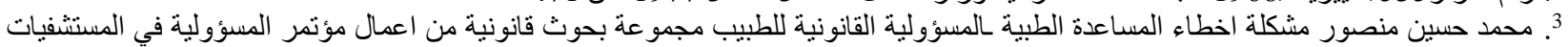

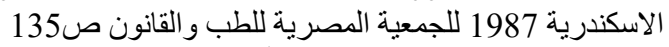

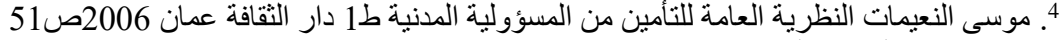

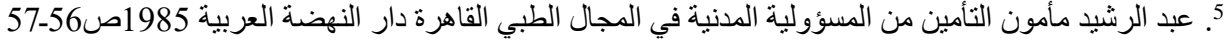

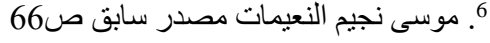


تحدث في مجال نشاطهم المهني المألوفة منها المتوقعة وغير المتوقعة ويتجسد ذللك جليا في عمليات الجراحة التجميلية التي

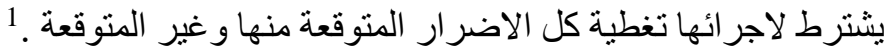

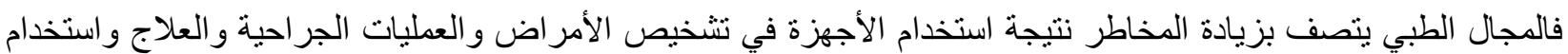

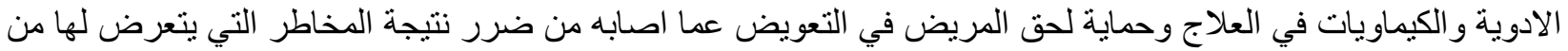

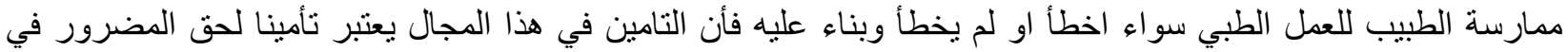



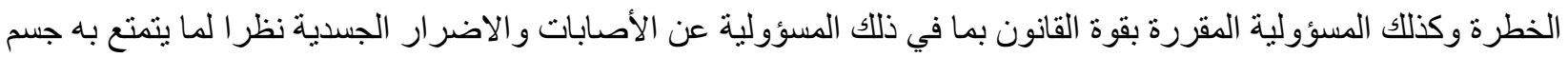

الأنسان من المعصومية وكانة

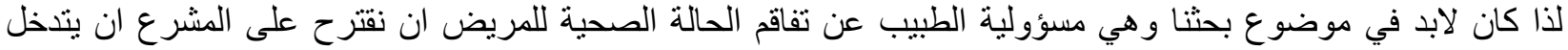

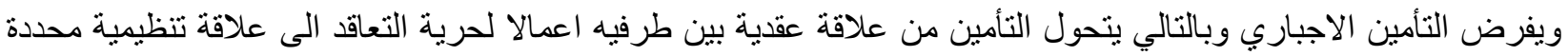

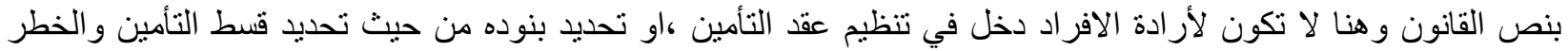

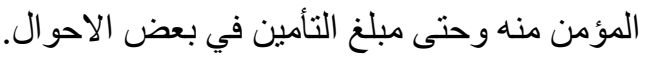

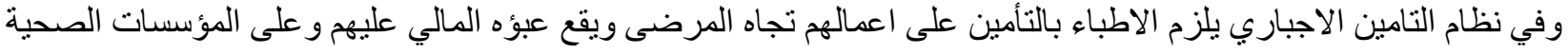

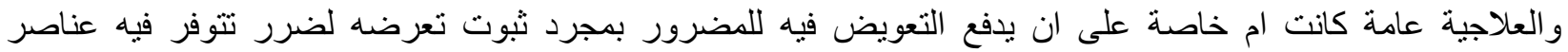

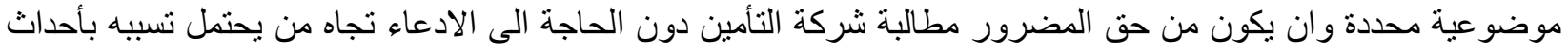

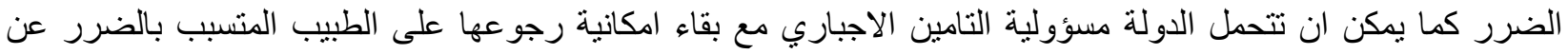

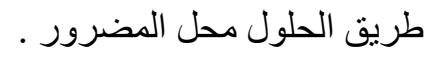

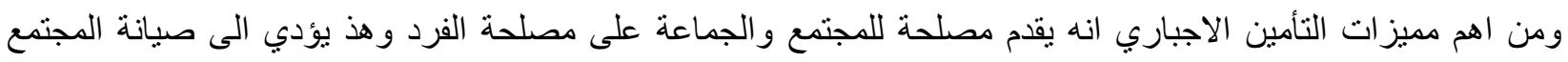

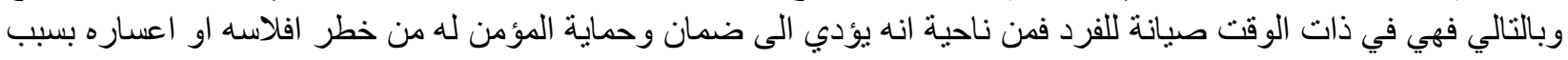

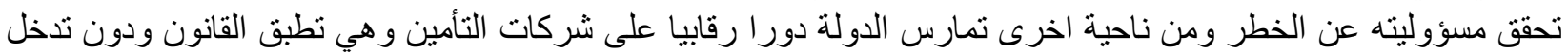

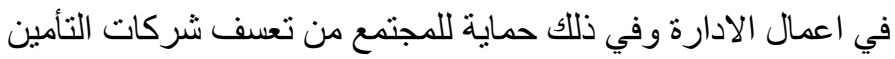

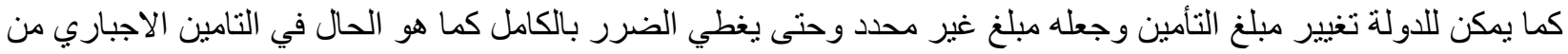

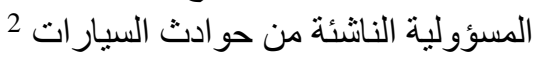
ولعل التجربة الامار اتية خير مثال على ذلك فقد صدر قانية التون التأمين الاجباري للطبيب من اخطاء المهنة المدنية فقد نصت المادة

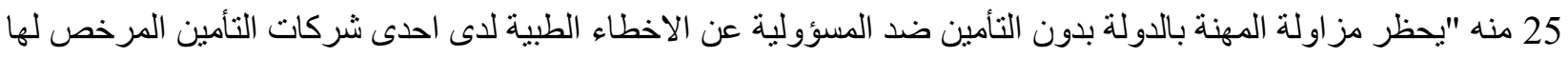

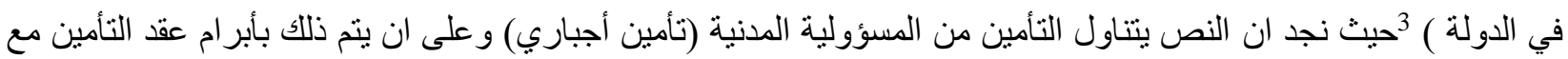

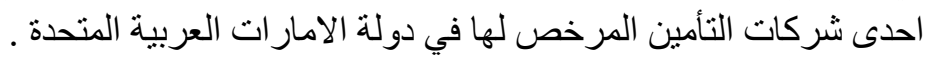

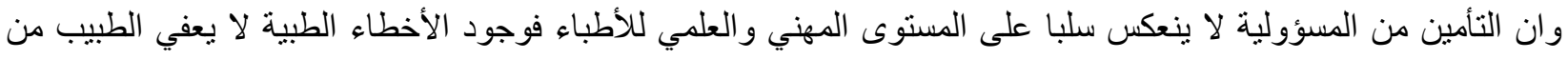

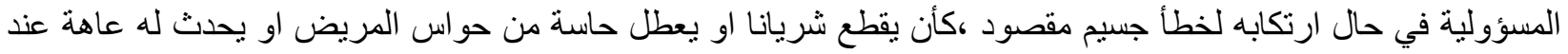

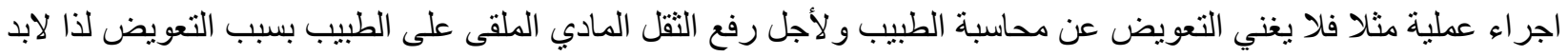

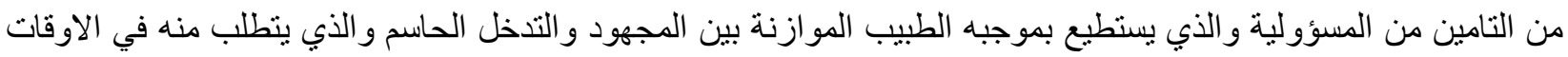

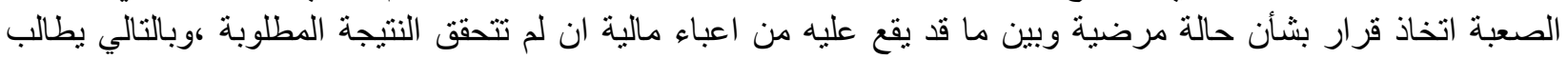

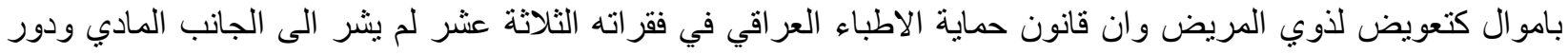

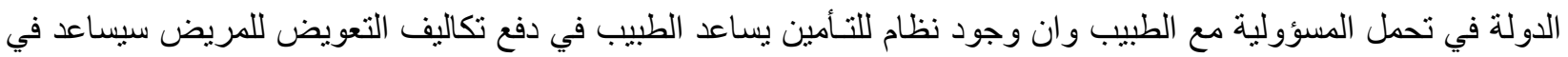
تخفيف العبء عن كاهل الطبيب على غرار المشر على الامار اتي 4

الخاتمة

1. زينب أحلوش التأمين الاجباري على المسؤولية المدنية المهنية في ظل مستجدات التطور وتز ايد المخاطر بحث منشور مجلة العلوم القانونية والسياسية



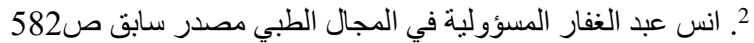



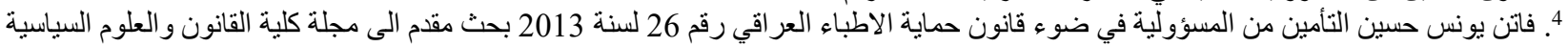
الجامعة العر اقية العدد5 2020 صن صن 15 
الحمد لله الذي بنعمته تتم الصالحات أما بعد فأننا توصلنا في نهاية بحثنا الموسوم مسؤولية الطبيب عن تقاقم الحالة الصحية

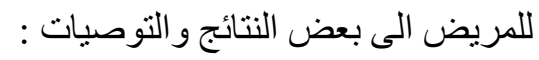

النتائج

1. لكل شخص الحق في ان يحتفظ بالمستوى الصحي الذي يتمتع بهاه ومن أجل ذلك فأن كل فعل يترتب عليه نقصان في

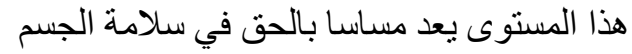
2. تعرف مسؤولية الطبيب عن تفاقم الحالة الصحية للمريض هي الحالة التي يرتكب فيها الطبيب فعلا يسبب تفاقم الحالة الصحية للمريض فيستوجب محاسبة القانون له و هي تقسم الى نو عين من المسؤولية مسؤولية جنائية ومسؤولية مدنية

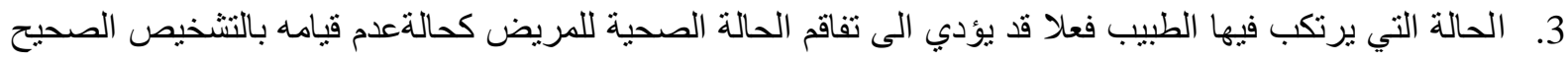
للمريض و الذي يترتب عليه اخذ العلاج غير الصحيح او في حال عدم مر اقبة المريض فأنه تترتب المسؤولية المهنية للطبيب

4. الخطأ الذي يرتكبه الطبيب ويؤدي الى تفاقم الحالة الصحية للمريض يحتبر خطأ مهنيا

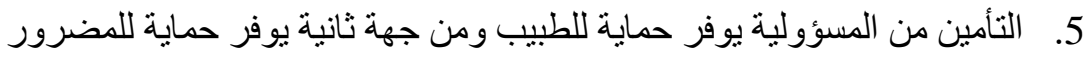

1. لابد من تحديد انواع الخطأ الطبي وبيان احكام الخطأ العادي والخطأ المهني وبيان عواقب الخطأ الطبي لخريجي كليات الطب

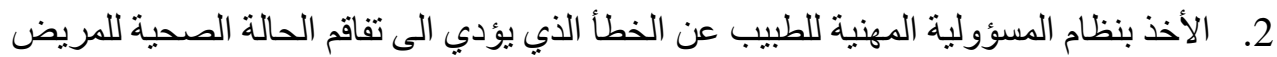

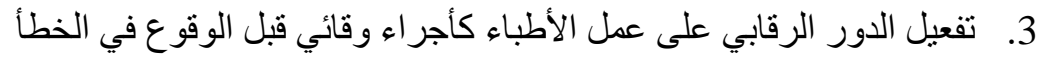

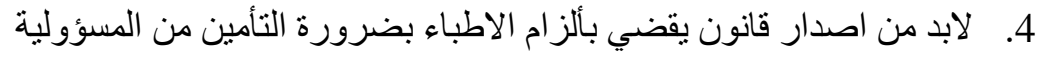

\section{المر اجع والتوثيقات}

1

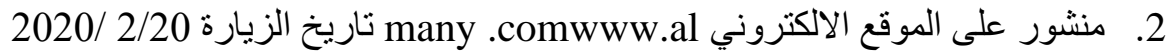

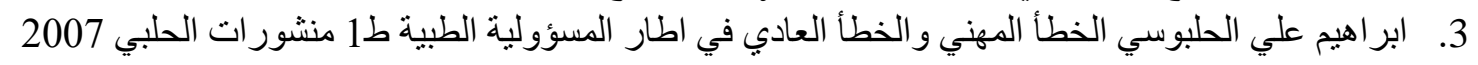

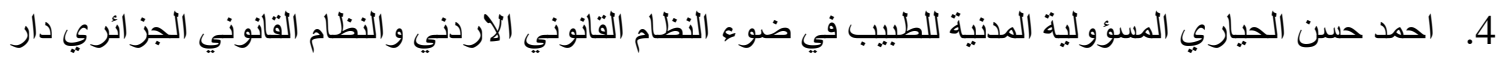
الثقافة عمان 2005

5. احمد شوقي عمر ابو خطوة القانون الجنائي والطب الحديث المطبعة العربية الحديثة القاهرة 1986

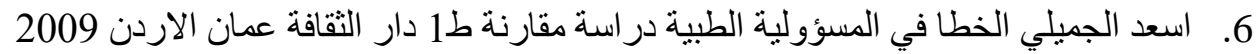

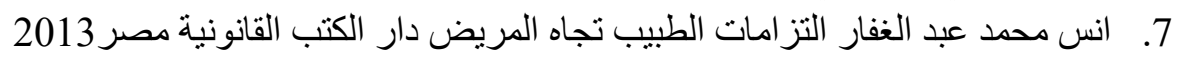



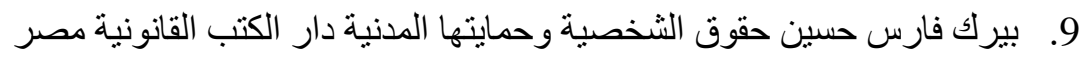

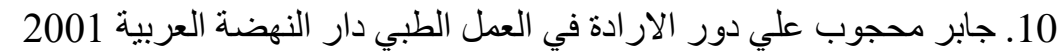

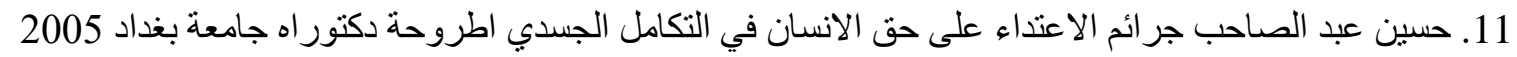

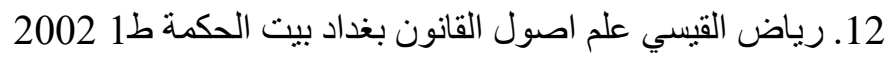

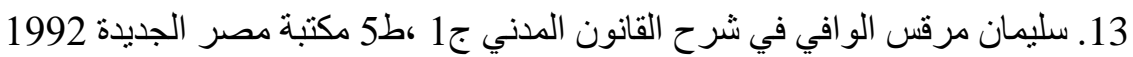
14. د.عبد الرزاق السنهوري -الوسيط في شرح القانون المدني الجديد ــصـادر الألتزام القاهرة دار النهضة العربية 2001 15. عبد الرشيد مأمون التأمين من المسؤولية المدنية في المجال الطبي القاهرة دار النهضة العربية 1985 
16. عبد السلام التونجي_المسؤولية المدنية للطبيب في الثريعة الاسلامية ـط1 سـنة 1966 17. عبد اللطيف الحسني وعاطف النقيب المسؤولية المدنية عن الاخطاء المهنية ط1 الركة العلمية للكتاب ،دار الكتاب اللبناني بيروت 1987.

18. عوض محمد جر ائم الاشخاص والامو ال (الكتاب الاول ) الاسكندرية دار المطبو عات الجديدة 1985

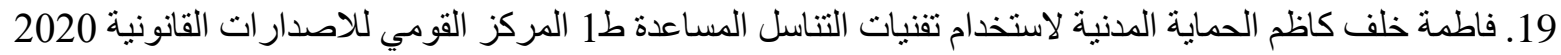

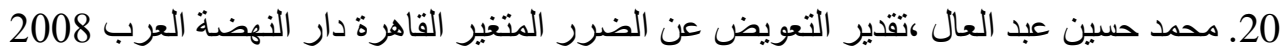

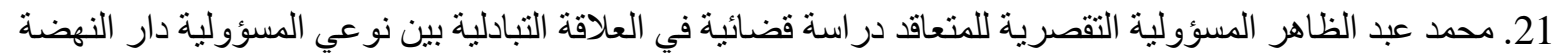

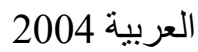

22. محمد منصور المسؤولية الطبية الاسكندرية دار الجامعة الجديدة للنشر 2001

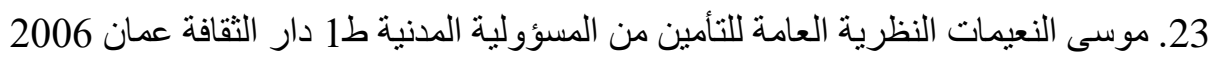

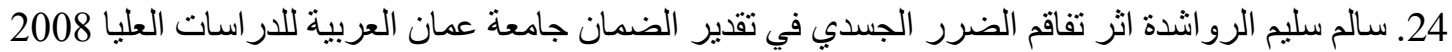

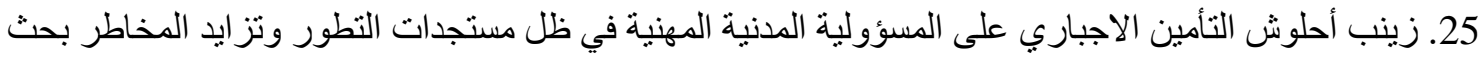
منشور مجلة العلوم القانونية و السياسية المجلد 11،العدد3 ديسمبر العالئ 2020 26. فاتن يونس حسين التأمين من المسؤولية في ضو ء قانون حماية الاطباء العر اقي رقم 26 لسنة 2013 بحث مقدم الى

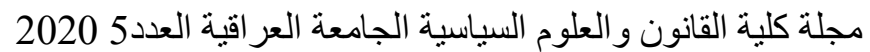
27. محمد القاسم الخطا الطبي في نطاق المسؤولية المدنية ،مجلة الحقوق و الثريعة جامعة الكويت ،العددالاول السنة الثالثة

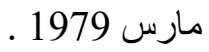

28. محمد حسين منصور مشكلة اخطاء المساعدة الطبية مالمسؤولية القانونية للطبيب مجمو عة بحوث قانونية من اعمال

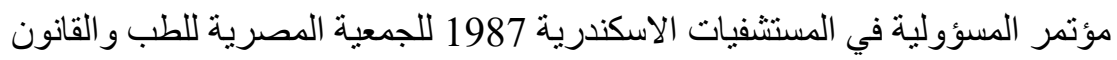
29. همام محمد يعقوب نظرة عن حالات قيام و انتفاء مسؤولية الطبيب في القانون المدني العر اقي بحث مقدم الى مجلة كلية

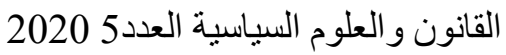

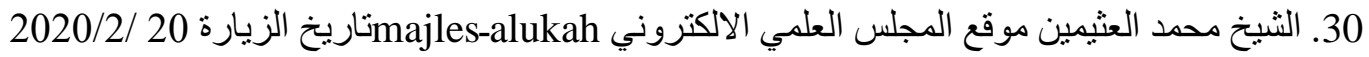

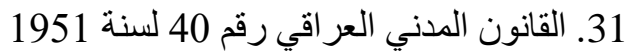
32. القانون المدني المصري رقانو لمني لسنة 1948 33. القانون المدني الفرنسي لسنة المني المن 1804 المعدل 34. قانون التأمين من المسؤولية الطبية في الامار ات العربة العربية المتحدة رقم 10 لسنة 2008

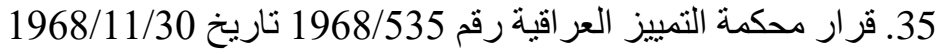

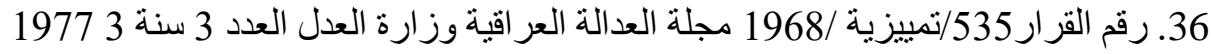

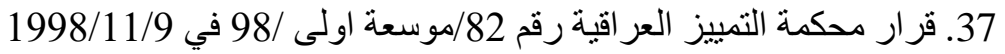




\title{
The Doctor's Responsibility for worsening the patient's health
}

\author{
Dr. Zena Hussin Alwan \\ Nahrain university/college of law \\ *Corresponding author E-mail: zena.h@nahrainuniv.edu.iq
}

\begin{abstract}
Submission date:14/4/2021
Publishing date:16/5/2021

Abstract:

The right to body safety is a legal status that enables the occupant within the limits of the law to maintain his physical integrity and the level of health he experiences with his physical and psychological knife, conveys the right to safety to all organs of the body and that prejudice to responsibility and because medical procedures require harm to the human body may raise the responsibility of the doctor when he makes a mistake that aggravates the patient's health and adapts this responsibility as a professional responsibility.
\end{abstract}

